\title{
Does the community-based combined Meeting Centre Support Programme (MCSP) make the pathway to daycare activities easier for people living with dementia? A comparison before and after implementation of MCSP in three European countries.
}

\begin{tabular}{|c|c|}
\hline Journal: & International Psychogeriatrics \\
\hline Manuscript ID & IPG-06-17-246.R1 \\
\hline Manuscript Type: & Original Research Article \\
\hline Date Submitted by the Author: & 21-Nov-2017 \\
\hline Complete List of Authors: & $\begin{array}{l}\text { Szcześniak, Dorota; Uniwersytet Medyczny im Piastow Slaskich we } \\
\text { Wroclawiu, Department of Psychiatry } \\
\text { Droes, R. M.; VU University medical center, Psychiatry } \\
\text { Meiland, F.J.M.; VU University medical center, General practice and Elderly } \\
\text { Care Medicine } \\
\text { Brooker, Dawn; University of Worcester, Association for Dementia Studies } \\
\text { Farina, Elisabetta; Fondazione Don Carlo Gnocchi, Santa Maria Nascente } \\
\text { IRCCS Clinical Research Center } \\
\text { Chattat, Rabih; University of Bologna, Psychology } \\
\text { Evans, Shirley; University of Worcester, Association for Dementia Studies } \\
\text { Evans, Simon; University of Worcester, Association for Dementia Studies } \\
\text { Saibene, Francesca; Fondazione Don Carlo Gnocchi, Santa Maria Nascente } \\
\text { IRCCS Clinical Research Center Milano, Lombardia, IT } \\
\text { Urbańska, Katarzyna; Uniwersytet Medyczny im Piastow Slaskich we } \\
\text { Wroclawiu, Department of Psychiatry } \\
\text { Rymaszewska, Joanna; Uniwersytet Medyczny im Piastow Slaskich we } \\
\text { Wroclawiu, Department of Psychiatry }\end{array}$ \\
\hline Keywords: & Dementia, Carers, Community care, Day Programs, Heathcare systems \\
\hline
\end{tabular}

\section{SCHOLARONE $^{\text {th }}$ \\ Manuscripts}


Title: Does the community-based combined Meeting Centre Support Programme (MCSP) make the pathway to day-care activities easier for people living with dementia? A comparison before and after implementation of MCSP in three European countries.

SZCZEŚNIAK, Dorota, PhD, dorota.szczesniak@umed.wroc.pl, Department of Psychiatry, Wroclaw Medical University, Wroclaw, Poland DRÖES, Rose-Marie, Prof., rm.droes@vumc.nl, Department of Psychiatry, EMGO institute for Health and Care Research, VU University medical center, Amsterdam, The Netherlands MEILAND, Franka, PhD, fj.meiland@vumc.nl, VU University medical center, Amsterdam, The Netherlands

BROOKER, Dawn, Prof., d.brooker@worc.ac.uk, Association for Dementia studies, University of Worcester, United Kingdom

FARINA, Elisabetta, PhD, efarina@dongnocchi.it, IRCCS S. Maria Nascente Don Gnocchi Foundation, Milan, Italy CHATTAT, Rabih, Prof., rabih.chattat@unibo.it, University of Bologna, Italy EVANS, Shirley B., PhD, shirley.evans@worc.ac.uk, Association for Dementia studies, University of Worcester, United Kingdom EVANS, Simon C., PhD, simon.evans@worc.ac.uk, Association for Dementia studies, University of Worcester, United Kingdom SAIBENE, Francesca Lea, MA, fsaibene@dongnocchi.it, IRCCS S. Maria Nascente Don Gnocchi Foundation, Milan, Italy

URBAŃSKA, Katarzyna, k.urbanska@hotmail.com, Department of Psychiatry, Wroclaw Medical University, Wroclaw, Poland RYMASZEWSKA, Joanna, Prof., joanna.rymaszewska@umed.wroc.pl, Department of Psychiatry, Wroclaw Medical University, Wroclaw, Poland

\author{
Corresponding author \\ Dorota Szcześniak \\ e-mail: dorota.szczesniak@umed.wroc.pl \\ tel.: +48717841628 \\ fax: +48 717841602 \\ Division of Consultation Psychiatry and Neuroscience \\ Department of Psychiatry \\ Wroclaw Medical University \\ Pasteura 10, 50-367 Wroclaw, POLAND
}




\begin{abstract}
Background: The 'pathway to care' concept offers a helpful framework for preparing national dementia plans and strategies and provides a structure to explore the availability and accessibility of timely and effective care for people with dementia and support for their informal carers. Within the framework of the JPND-MEETINGDEM implementation project the pathways to regular day care activities and the Meeting Centres Support Programme (MCSP), an innovative combined support form for people with dementia and carers, was explored.
\end{abstract}

Methods: An exploratory, descriptive, qualitative, cross-country design was applied to investigate the pathways to day care in several regions in four European countries (Italy, Poland, UK and the Netherlands).

Results: Before implementation of MCSP, of the four countries the UK had the most structured pathway to post-diagnostic support for people with dementia. MCSP introduction had a positive impact on the pathways to day care activities in all countries. MCSP filled an important gap in post-diagnostic care, increasing the accessibility to support for both people with dementia and carers. Key elements such as programme of activities, target group and collaboration between health care and social services were recognised as success factors.

Conclusions: This study shows that MCSP fills (part of) the gap between diagnosis and residential care and can therefore be seen as a pillar of post-diagnostic care and support. Further dissemination of Meeting Centres in Europe may have a multiple impact on the structure of dementia services in European countries and the pathways to day care for people with dementia and their carer(s).

Keywords: Dementia; Carers; Community care; Day Programs; Heathcare systems

\title{
Introduction
}


The main goal of dementia care and governmental policies is to prolong the autonomy of the person living with dementia, to support them and their families to adapt to the changes dementia brings into their lives and to promote their, and their informal carers', quality of life. In general, most people living with dementia are cared for in their own homes, (Prince et al., 2015) supported by informal (unpaid) carer. This can entail significant social, physical and emotional consequences, with carers being at risk of developing health problems (delPino-Casado et al., 2011; van der Lee et al., 2014). The challenges of coping with the changes dementia brings in people's life, both for persons with dementia and their carers and in some cases also the absence of carers are two of the main reasons for people with dementia being admitted into a nursing home. Timely and effective support for unpaid carers and care for people with dementia are important to ensure that people with dementia can continue to live in the community for as long as possible.

The 'pathway to care' concept may offer a helpful framework for preparing national plans and strategies in dementia. It has become increasingly influential in many domains of health service management including the planning, resourcing and delivery of continuing care. In the literature, there are different perspectives on dementia care pathways (see Samsi and Manthorpe, 2014). Schrijvers et al. (2012) refer to the process innovations that focus on improving the organisation of care processes, which is consistent with the definition of the pathway to care described in this paper. According to authors of the World Alzheimer Report (Prince et al., 2016) "the overall objective of a care pathway in dementia would be to provide high quality care that is responsive, flexible and continuing, with the aim of maximising independence and participation, and optimising health and quality of life for patient and carers throughout the disease" (p.13). Although care pathways may differ between and within countries there are also commonalities, common steps, which can be described as follows:

1. Screening assessment (identification of early symptoms, or risk, of dementia).

2. Diagnostic assessment.

3. Disclosure of the diagnosis to the person with dementia and/or his/her family.

4. Post-diagnostic support.

5. Long-term care.

People with dementia often receive a diagnosis several years after the first symptoms of the disease appear (Millard and Baune, 2009). In recognition of this, the ALzheimer's COoperative Valuation in Europe (ALCOVE) Joint Action, co-financed by the European Commission, produced a set of evidence-based recommendations for policy makers on dementia. Evidence from research and practice (Brooker et al., 2014) suggested that all citizens should have access to accurate diagnosis at a time when it can be of most benefit to them. The term timely diagnosis is used to reflect this. The diagnosis can help citizens and their families make sense of what is happening, make lifestyle changes and plan for the future. Principles central to improving quality of life and managing the impact of the disease are:

1. Decreasing stigma.

2. Respecting the rights of the individual.

3. Recognising that how the diagnosis is given will impact on adjustment.

4. Providing post-diagnostic support for the person and their family/significant others. However, lack of knowledge, skills and resources among both general practitioners and family and other informal carers (Millard and Baune, 2009; Wilcock et al., 2013) lengthen the journey from dementia diagnosis to access to adequate services, including day care. What is 
more, in many places around the world the dementia care pathway ends just after the diagnostic assessment process, as there is little or no post-diagnostic support, and thus also no day care. In many countries there is still a need to organise a multidisciplinary, coordinated system of care for people with dementia in the form of an evidence-based pathway. It is also essential to coordinate the care provided by health and welfare services. This could be done by general practitioners or other professionals such as healthcare assistants, case managers or district nurses or by introducing an integrated, positively evaluated model of care. Moreover, good pathways to care in dementia should be responsive to changes that occur throughout the course of the disease (Prince et al., 2016) and care should be proactive and delivered closer to home (OECD, 2015).

The Meeting Centre Support Programme (MCSP) may be seen as a good example of integrated post-diagnostic support for people with mild to moderate dementia and their carers (Dröes et al., 2004b). The combined and intensive support programme consists of: (1) a social club where people with dementia receive person-centred, emotion-oriented care and can participate in recreational and creative activities, and receive psychosocial interventions, such as psychomotor therapy, reminiscence and cognitive stimulation; (2) a series of information meetings on topics relevant to living with a person with dementia (e.g. dementia symptoms, behaviour changes, treatments, available services, ethical and juridical aspects), and ongoing peer discussion groups for informal carers; (3) a weekly individual consultation hour for personal advise or support, (4) a monthly (or two-monthly) centre meeting, where people with dementia, informal carers and staff of the meeting centres meet, share their experiences and can express specific needs and wishes, and (5) social outings and festivities. The MCSP approach is based on the Adaptation-coping model and aims to - support people with dementia and their carers in dealing with the functional, emotional and social consequences of dementia in different adaptation areas, such as dealing with disabilities, developing an adequate care relationship with caregivers, preserving an emotional balance and positive self-image, developing and maintaining social relationships and dealing with an uncertain future (Dröes at al., 2010). Depending on the individual adaptation challenges and needs people experience (summarised as the psychosocial diagnosis), the support focuses on (re-)activation, (re-)socialisation and/or promotion of the affective functioning of the person with dementia, and information and practical, emotional and social support for their carers (Dröes et al., 2014). MCSP is offered in an accessible, socially integrated, location (e.g. a general community centre, a space near the church hall or a senior's centre), which facilitates social inclusiveness and community integration. It is organised by a small permanent professional team of staff trained in dementia care and trained volunteers. To counteract the fragmentation of care and welfare services, close collaboration with other care, welfare and voluntary organisations in the region that offer dementia care is set up and maintained according to a collaboration protocol.

In the Netherlands, the MCSP, offering amongst other things day care activities ${ }^{1}$ at a socially integrated location in combination with carer support, was introduced more than 20 years ago. This resulted in people with dementia being referred to day care activities in the Meeting Centres by professional carers (e.g. general practitioner, memory clinics, district or psychiatric nurse) at an earlier stage in their dementia compared to the regular day care offered in nursing homes. Up to $39 \%$ of carers came to the Meeting Centre with their family

\footnotetext{
${ }^{1}$ For the purpose of this paper, we adopted the following working definition of day care activities: Any program providing day-time meaningful activities to its users and opportunities to socially engage.
} 
member with dementia without formal referral from a professional (Dröes et al., 2004a). Also, carers attended the Meeting Centre because they became aware of their own need for support after reading articles in the local newspaper on the combined support programme. Moreover, contact with referrers improved as a result of close collaboration with other care and welfare organisations. This made it easier to initiate the MCSP after diagnostic assessment, to arrange tailored care packages at home and to organise support activities for the informal carers such as psycho-educational groups. Prior to the MCSP these services were often incidentally organised by different providers, if available at all. Once MSCP collaboration was in place, monthly information and support meetings were organised in the Meeting Centres which were open to the wider community (Dröes, 1996; Meiland et al., 2005).

\begin{abstract}
Aim of the study
This study aimed to provide insight into the impact of care process innovation, in this case the implementation of MCSP, on the pathways to post-diagnostic care and support for people affected by dementia. It was hypothesised that this impact could be different in different health care and welfare systems in different countries, where other pathways to care exist, and that other key-elements of MCSP may cause improvements in the pathways to care in these countries. Moreover, the study aimed to provide information on the period in the dementia trajectory that people with dementia and carers benefit from MCSP. The study was therefore carried out in different European countries and regions with different health care systems (Milan and Bologna in Italy, Wroclaw in Poland, and Worcestershire in the UK). Organisations in these regions participated in a European collaborative implementation study the MEETINGDEM project (funded by the EU Joint Programme - Neurodegenerative Disease Research - JPND), which aimed to adaptively implement and evaluate the Dutch MCSP model in different European countries (Dröes et al., 2017; www.meetingdem.eu).
\end{abstract}

The study intended to answer the following questions:

1. What are the pathways to regular dementia day care activities and support in the selected regions in three European countries (Italy, Poland and the UK) before the implementation of MCSP?

2. Do the pathways to regular day care and to MCSP differ from each other in the three countries and from the pathway to MCSP in the Netherlands?

3. Does introducing MCSP improve the accessibility to day care activities for people with dementia and support for their carers in the selected regions in three involved countries?

4. If there are improvements in the pathway/accessibility to day care activities and support after implementing MCSP, what key elements of the MCSP have affected these improvements?

5. What is the expected ideal period in the trajectory of the dementia journey for people in terms of severity of dementia to benefit from the MCSP? 


\section{Methods}

\section{Study design}

An exploratory, descriptive, qualitative, cross-country design was applied among several regions of four European countries (Italy, Poland, the UK and the Netherlands) differing in demographic composition, dementia health care systems and provision of social welfare services.

\section{Data collection and procedure}

The methodological approach of the study was based on a consensus method (Jones and Hunter, 1995) used previously in developing a Mapping System in the "RightTimePlaceCare (TTPC; the EU $7^{\text {th }}$ framework) project (Hallberg et al., 2013) and in the Actifcare (Access to Timely Formal Care, the JPND programme) project (Kerpershoek et al., 2016). The MEETINGDEM project teams in each country were used as panels of experts for the first data collection. After that agreement on terms and a procedure to describe the pathways to care in the present study was achieved.

The procedure consisted of the following steps and aims:

- Regarding research question 1

Step 1 (before the implementation of MCSP): to collect information on the existing dementia day care activities and support services (that is the social service system) and illustrate graphically pathways to dementia day care activity services in the regions where MCSP would be implemented in the three countries (I, PI and UK).

For the Italian pathways to day care, information about two regions, Lombardia and Emilia Romagna, was collected. a) A neurologist and a psychologist from the partner organisation in Milan summarised the situation in the Lombardia Region. This was based on two decades of experience of the Don Gnocchi Foundation (Alzheimer Assessment Unit, General Neurology Outpatients' Service, and Outpatients' Department for Diagnosis and Treatment of Cognitive Disorders); the networks in which the neurologist and psychologist are involved (Italian Neurologist Association for dementia, Italian Geriatricians, families' associations, and a project of standardization of pathways to care in Milan). b) Two psychologists from the University of Bologna mapped the pathways to day care in the Emilia-Romagna region based on experiences in the Alzheimer's café network, and the regional plan for dementia. The pathway to dementia day care and support in Poland was mapped by the Wroclaw Medical University team (a psychiatrist and two psychologists) based on their clinical experience as well as on interviews with day care providers in Wroclaw (one day care organised in a Mental Health Hospital; two organised by the Association of Our Lady of Perpetual Succour 'Friends of Seniors'; one organised by the Municipal Social Welfare and the Municipal Social Service Centre in Wroclaw).

In the UK pathway in dementia care and support was based on published recommendations from the National Dementia Strategy for England (2009). The pathway described was the interpretation of the national recommendations in Worcestershire. The Worcestershire Early Intervention Dementia Team worked closely with the Association for Dementia Studies at the University of Worcester to provide best practice in dementia diagnosis and post diagnostic support. The described pathway was informed particularly by the ALCOVE recommendations (Brooker et al., 2014) and includes referral to day activities and services in 
Worcestershire (Note: there are many different pathways to dementia care and day care across the UK).

Step 2: to create a standard template to map and compare pathways to day care activities and support. We adopted a modified version of the template that was used in the Actifcare (Access to Timely Formal Care, the JPND programme) project (www.actifcare.eu), which aims to analyse the pathways to care for people with dementia and their families.

Step 3: to achieve consensus between representatives from the research teams in the four countries involved in MEETINGDEM (I, PL, UK and NL) on the final version of the template on pathways to dementia day care activities via e-mails and teleconferences. The modified template enables assessment of the existing formal structures of dementia care services in the following areas:

a. diagnostic and therapeutic settings,

b. home care and support,

c. informal carers and

d. civil activities (voluntary and self-help unpaid or paid organisation providing care and service to persons with dementia disease).

- Regarding research question 2

Step 4 (9 months after implementation of MCSP): to apply the modified Actifcare template to collect the data on pathways to day care activities in each region and country involved, before and after implementing MCSP (I, PI and the UK). The information on pathways to MCSP in the Netherlands was based on a multi-centre implementation study carried out in 2000-2003 (Dröes et al., 2004b).

- Regarding research question 3, 4 and 5

Step 5: to organise an expert panel per country with members from the research teams, Meeting Centre coordinators, informal carers, to answer the research questions (which were prepared on a worksheet to standardise the procedure to be followed in the different countries) separately for each region. The data from the worksheets as well the minutes from the expert panel meetings in each country were summarized in 3 reports. These were taken into account in the final thematic analysis that aimed to identify the key elements of MCSP that seem to have affected the potential changes/improvements in the pathways to day care activities and to identify the ideal period in the trajectory of the dementia journey to benefit from MCSP.

\section{Results}

Existing pathways to dementia care, including day-care activities and support, in three European countries before implementation of MCSP (research question 1)

In Italy, a national dementia plan was published in 2014 but it has been not yet been fully implemented. In Poland, there are no official national guidelines for dementia care. However, the Polish Alzheimer's Society and Group of Polish professionals (psychiatrists, neurologists, geriatrists, psychologists) have created recommendations, based on standards 
of diagnostics and care in dementia, and have already published it in Polish medical journals and guides for doctors and psychologists. However, no official regulations and procedures were available. The dementia care pathway in the UK was based on the National Dementia Strategy for England, which informed the regional Worcestershire strategy.

Below the pathways to dementia care, including day-care activities and support, are described for Italy, Poland and UK.

$\underline{\text { Italy }}$

Figure 1 shows the pathway from screening/diagnosis to day care centres in 2 Italian Regions.

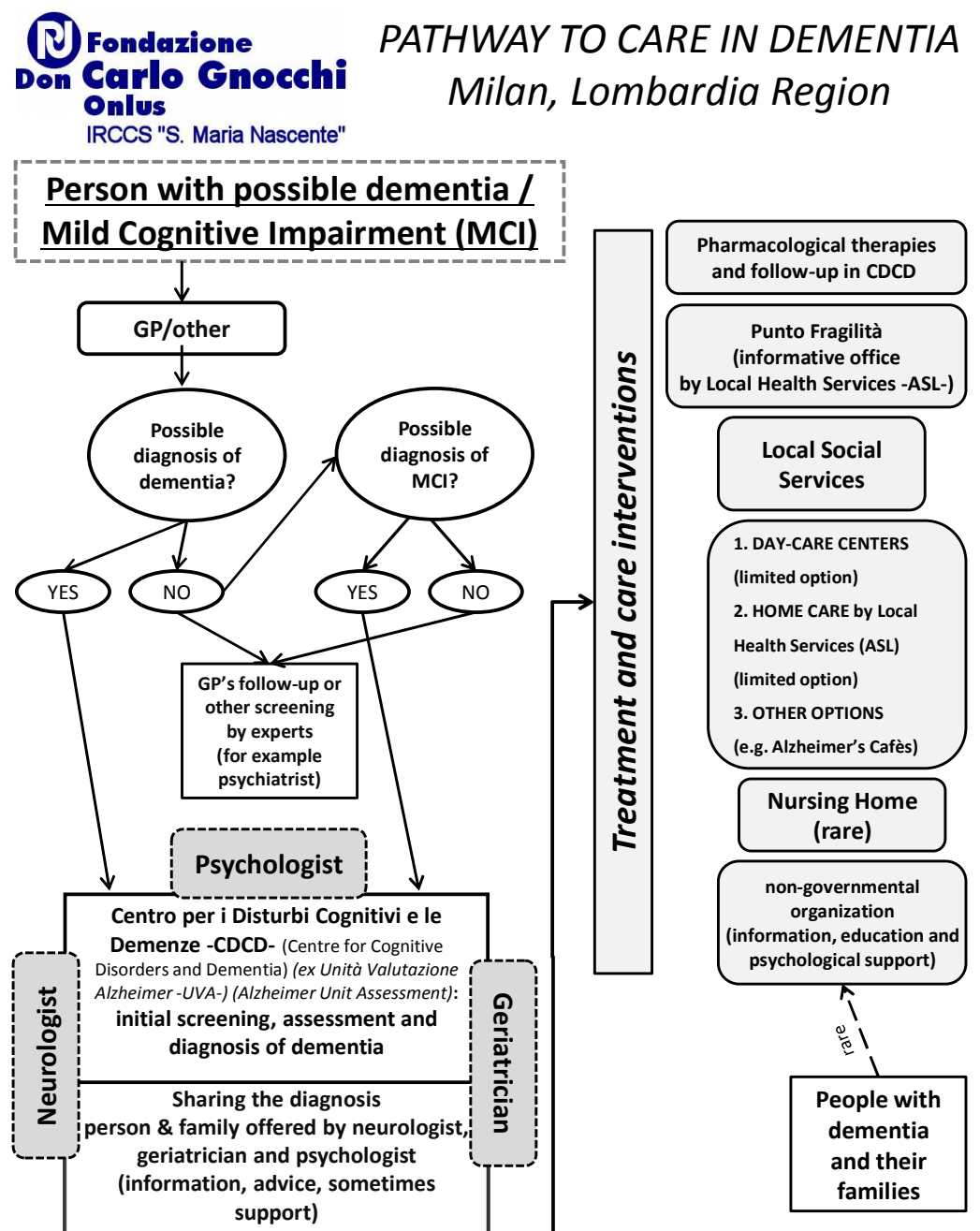


Figure 1a and b. Pathway to Dementia Care in two regions in Italy (a. Lombardia region; b. EmiliaRomagna region)

In Italy the health care and welfare organization is mainly regionally based, which implies differences between the two regions in the organization of care and the coordination between health and welfare systems. Therefore both pathways to dementia care in these 2 regions are presented

In (a) the Lombardia region, people with possible/suspected dementia usually start a diagnostic process with the general practitioner (GP). After initial screening, the physician refers the patient to a Centro per i Disturbi Cognitivi e le Demenze/ Centre for Cognitive Disorders and Dementia-CDCD. CDCD are "outpatient memory clinics" specialized in diagnostics of Alzheimer's disease and other dementias. A neurologist or a geriatrician working in CDCD usually makes the final diagnosis. Frequently a psychologist takes part in the diagnostic process and people working in CDCD collaborate with GPs in dementia treatment. Sometimes the GP can send persons with cognitive disturbances to a neurologist or geriatrician who does not work in CDCD. Alternatively people with suspected dementia or mild cognitive impairment $(\mathrm{MCl})$ may go directly to a neurologist or geriatrician without consulting a GP. When the diagnostic process is completed the diagnosis is communicated to the person with dementia and the carer (but mostly only to the latter). The CDCD plans follow-up sessions (usually every 6 months) to monitor the progress of the disease and to suggest further interventions. In some cases the specialists working in the CDCD will refer people with dementia to care services in the post-diagnostic phase. Recently, the Lombardia 
region introduced the possibility of hospital rehabilitation stay for people with dementia with behavioural problems or acute illnesses ("Intermediate Rehabilitation-Type 5") and limited rapid hospital stay for acute behavioural discompensation (e.g. delirium). In the Lombardia region, the pathway to day care is very "informal" and supported by relatives and friends even though CDCD personnel sometimes offer information on care resources to the family. The support from day care centres is often the consequence of sharing the diagnosis with family and friends. The most available are day cares provided by Local Health Services or sometimes by other services or associations (above all nongovernmental organizations). In some cities (e.g. Milan)/regions the Local Health Services and Municipality offer other services (e.g. Home Care, Information Points). Alzheimer's Cafes organized by Alzheimer associations also offer some activities to people with dementia and limited respite to their families.

Moreover, in some cities (e.g. Milan and Brescia), in recent years, Municipalities promoted a new project (PDTA: Percorso Diagnostico Terapeutico Assistenziale; Diagnostic and Therapeutic pathway) in order to meet the needs of people with dementia and to support their families by integrating health care (Local Health Services -ASL-) with the social and health contribution of the Municipality. The aim of this project is to create and integrate a network system composed of public resources (Municipality, ASL and hospital) and private social associations and cooperatives, to promote and disseminate mutual synergies.

In the Emilia-Romagna region, since 2014 in the revised version of the regional dementia plan (first issue in 1999), a more structured "flow chart" has been adopted. The first contact is still the GP who screens for possible cognitive impairments. If the screening is positive, then the person with dementia and family carer are referred to the Centre for Cognitive Disorders and Dementia (CDCD), which is the core service along the pathway (see fig. 1). This centre, as in Lombardia, is involved in diagnostics, diagnosis disclosure and early intervention for persons with dementia and carers and, in Emilia Romagna, also in the referral to other services (social care, Alzheimer associations and municipality services) for further support. When the dementia diagnosis is confirmed it is communicated to the person with dementia and/or to the carer (but, as in Lombardia, mostly only to the carer). Available options for treatment are given to both, as well as information about the available services in the local area. The CDCD also plans a follow-up session to monitor the progress of the disease and to suggest further intervention. Following this phase the person with dementia and carer are invited to contact the social care desk (a municipality service) in order to receive further information about the available support at home or for participation in other initiatives. A multidimensional assessment team (MAT; geriatrician, nurse and social worker) is in charge to evaluate the severity of the disease and the need for care and support by day care and residential care. The activities of the CDCD and MAT are mostly concentrated on the diagnostic, early post-diagnostic and severe phase of the disease. However, during the mild and moderate phase of the disease the person with dementia and carer have to rely on locally available services without a structured plan of support. The mental health services are mainly involved in dementia care for crises or during hospital stays. In Emilia Romagna, local initiatives supported by the local Alzheimer association or other local authority offer interventions for family carers and the person with dementia (such as cognitive stimulation). Since 2005 a model of 'meeting places' was developed in the region based on the Dutch meeting centres concept, but with limited availability, i.e. for only half a day per week. 
Poland

In Poland, the pathway to dementia day care activities starts with a visit to a GP or another physician. When a person is suspected of having a cognitive impairment he/she is referred to a specialist such as a neurologist or psychiatrist for the screening assessment. Frequently a psychologist takes part in the diagnostic process, mostly in cooperation with a specialist such as a psychiatrist. There are no trained old age psychiatrists in Poland, although there are some psychiatrists or neurologists who work predominantly with people living with dementia. It is important to note that there are a very small number of geriatricians in Poland - less than 200 in the whole country compared to 2681 neurologists and 2653 psychiatrists (Central Statistical Office, 2015). As in Italy, people with dementia tend to share the diagnosis of dementia with their relatives, but post-diagnostic support is very limited in Poland. In many cities, such as Wroclaw, which is the largest city in western Poland, there are very limited public day-care centres for people with dementia available (e.g. in Wroclaw there is only one day centre). People with dementia can also attend the day-care activities organised by one of the two non-governmental organisations in Wroclaw and by the single welfare service. People with dementia are referred to these centres by welfare organisations, medical doctors, psychologists or they can self-refer, but in all cases they need a medical certificate to be admitted to the day care centre. The informal carers generally receive only information and advice; there are no services to support carers emotionally, socially or practically during the dementia journey.

Very often the family is seen as an information channel for seeking these types of care. There are no clear guidelines for professionals regarding post-diagnostic care.

\section{PATHWAYS TO CARE IN DEMENTIA Wroclaw Medical Univeristy}
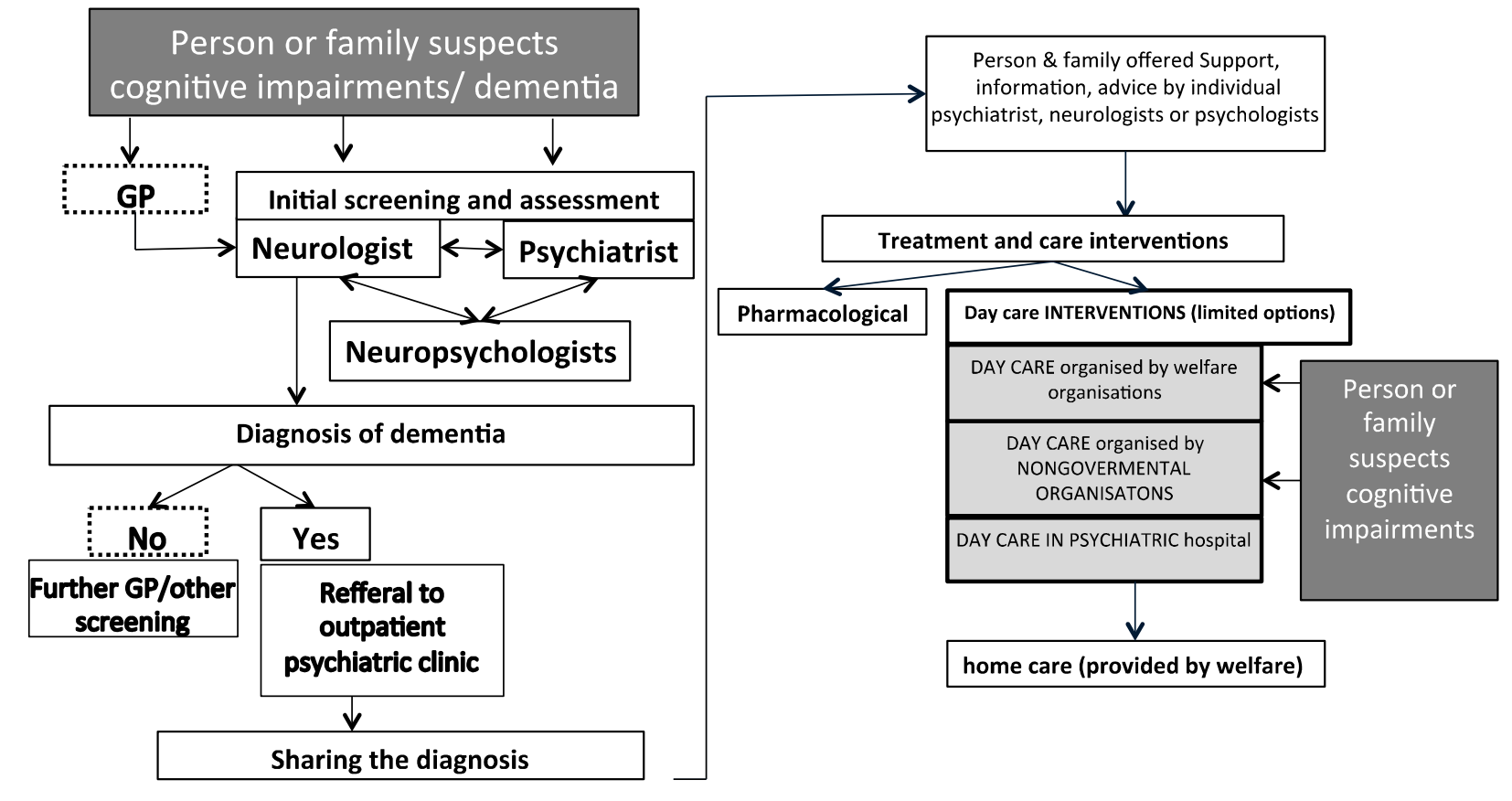

Figure 2. Pathway to Dementia Care in Poland (Wroclaw) 


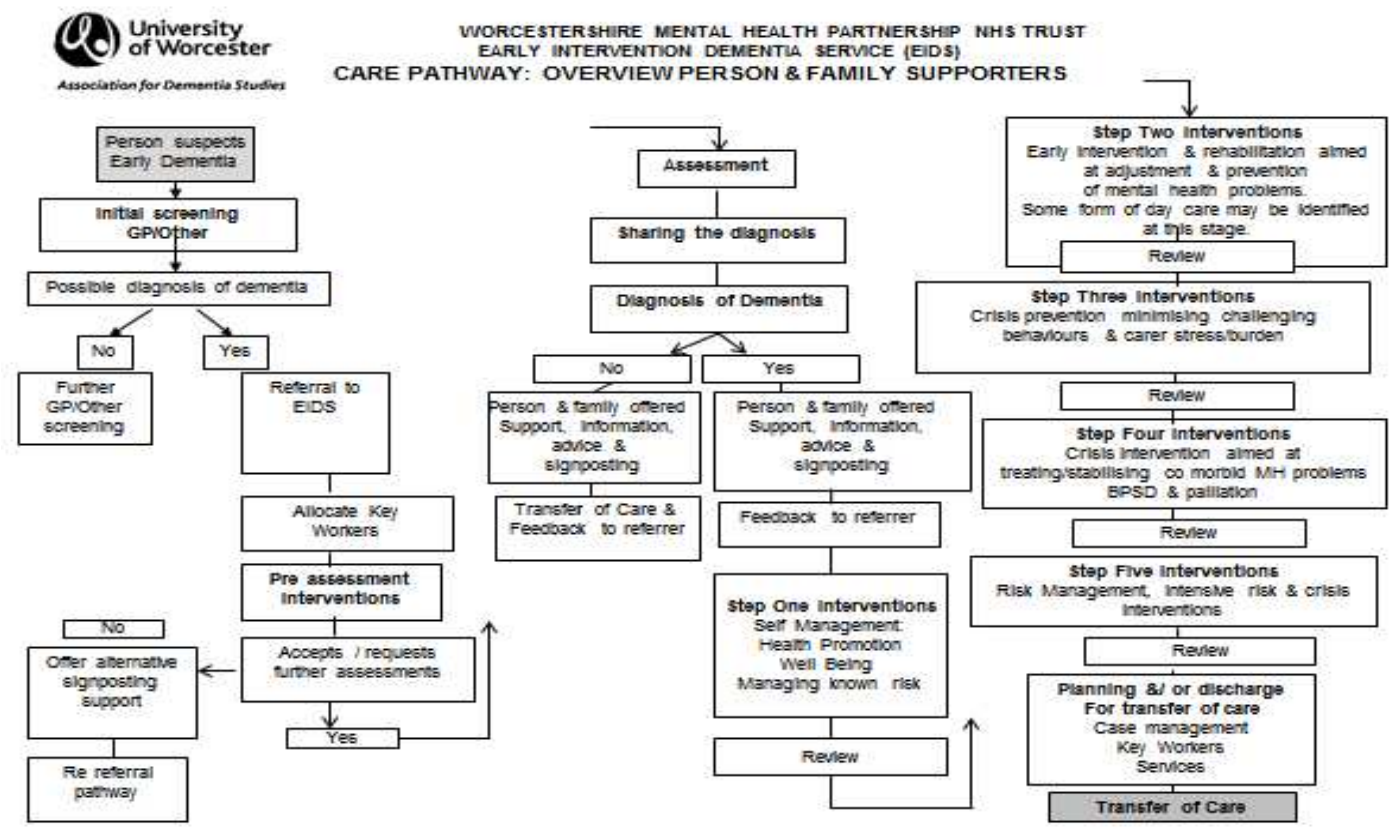

Figure 3. Pathway to Dementia Care in the UK (Worcestershire)

\section{United Kingdom}

In the UK, clinical services for people with dementia are delivered by the National Health Service, coordinated by a GP. All pathways in England are based on the National Dementia Strategy (2009) guidance but there are many local variations within this. The pathways in Scotland, Wales and Northern Ireland are different again in detail. Local services are commissioned according to population needs. Memory Assessment Services are widespread with targets set for diagnosis rate improvements in each locality. Post-diagnostic support is less standardised. Currently, different types of post-diagnostic interventions are delivered by a variety of different agencies from statutory, third sector, voluntary and community groups. Alzheimer and Memory Cafés are increasingly widespread offering monthly meetings. Dementia Advisers and support workers are commissioned in many areas to offer signposting and low-level support on an individual family basis. There is a growth civic activity in local communities taking action to become "Dementia Friendly" with local businesses and community service providers taking signing up to become "Dementia Friends" based on an hour long awareness session coordinated by the Alzheimer's Society. These developments at a local level tend to be organic rather than systematic. Whilst this can mean that support and interventions grow to meet local need, there is a danger that these initiatives are not developed on a sustainable footing to really deliver post-diagnostic effective interventions at this critical time. If different stakeholders do not collaborate then there is a risk that efforts are duplicated or that people living with dementia still do not know how to access support.

The pathway described in Figure 3 is the one that is commissioned within Worcestershire. Initial assessment is undertaken by the GP, who would carry out a simple cognitive assessment and undertake physical health checks. The doctor uses clinical judgement to 
decide whether to refer the person for specialist assessment. Those for whom a diagnosis seems likely are referred to the Early Intervention Service for Dementia (EIDS) which incorporates a Memory Clinic and Assessment Service. In some cases, the person may already be known to the specialist Community Mental Health Team and may be referred to EIDS via this route. The EIDS team consists of a team manager, consultant psychiatrist and specialist registered mental health nurses, occupational therapists, a support worker and a clinical psychologist. A key worker is appointed to take the individual and their family through the assessment process. If a diagnosis of dementia is not confirmed, the patient and their family are offered support, information, and signposting to appropriate services and care is transferred back to their GP. Where a diagnosis is confirmed, the person with dementia and their family are offered support, information and signposting, including referral to a Dementia Advisor.

The following options are available dependent on need and complexity of need:-

1. self-management, health promotion, wellbeing strategies and risk management.

2. early intervention and rehabilitation aimed at adjustment and prevention of mental health problems. This may involve recommendations for day care or support at home. If the level of need reaches the criteria for the allocation of funding (personal budget) from the local social care fund then this will be funded through this source. Alternatively people fund care themselves.

3. intervention to minimise BPSD and to reduce carer stress

4. crisis interventions to address co-morbid mental health problems, BPSD and palliative care needs.

5. discharge or transfer of care.

Comparison of pathways to usual day care and the Meeting Centres Support Programme in four European countries (research question 2)

Table 1 shows the comparison of official structures of dementia care services for community dwelling people with dementia available in the four countries/regions involved in the study: Italy, Poland, United Kingdom and the Netherlands. The structures/care services are described with respect to the following areas: (a) diagnostic and therapeutic setting, (b) home care and support, (c) informal carers and (d) civil activities. In addition, the pathways to usual dementia day care activities and MCSP are shown. 
Table 1. The description of structures of dementia care services in the four countries and the pathway to dementia day care activities and Meeting Centres

\begin{tabular}{|c|c|c|c|c|c|c|c|c|c|c|c|}
\hline \multirow{2}{*}{\multicolumn{2}{|c|}{ Structures of dementia care service }} & $\begin{array}{l}\text { Italy } \\
\text { (I) }\end{array}$ & $\begin{array}{l}\text { Poland } \\
\text { (PI) }\end{array}$ & The United Kingdom (UK) & \multicolumn{3}{|c|}{$\begin{array}{l}\text { Referral to } \\
\text { usual day care } \\
\text { activities }\end{array}$} & \multicolumn{4}{|c|}{$\begin{array}{l}\text { Referral to Meeting } \\
\text { Centre }\end{array}$} \\
\hline & & Is this service available? & & & 1 & $\mathrm{PI}$ & UK & 1 & $\mathrm{PI}$ & UK & $\mathrm{NL}^{*}$ \\
\hline \multirow{3}{*}{$\begin{array}{l}\text { Diagnostic } \\
\text { and } \\
\text { therapeutic } \\
\text { setting }\end{array}$} & $\begin{array}{l}\text { General Practitioners' } \\
\text { practice }\end{array}$ & Yes & Yes & Yes & + & + & + & + & + & + & + \\
\hline & $\begin{array}{l}\text { Specialised Physicians } \\
\text { practice }\end{array}$ & Yes & Yes & Yes & - & + & + & - & + & + & + \\
\hline & $\begin{array}{l}\text { Outpatients clinic } \\
\text { specific for dementia }\end{array}$ & $\begin{array}{l}\text { Yes/ } \\
\text { known as CDCD or } \\
\text { Geriatric Unit Evaluation }\end{array}$ & $\begin{array}{l}\text { Yes/ but limited options } \\
\text { in outpatient mental } \\
\text { health units }\end{array}$ & $\begin{array}{l}\text { Yes } \\
\text { Widespread Memory } \\
\text { Assessment Services }\end{array}$ & + & + & + & + & + & + & + \\
\hline \multirow{8}{*}{$\begin{array}{l}\text { Home care } \\
\text { and } \\
\text { support }\end{array}$} & $\begin{array}{l}\text { Healthcare } \\
\text { professionals }\end{array}$ & Yes & $\begin{array}{l}\text { Yes / but not specialised } \\
\text { in dementia / social } \\
\text { workers }\end{array}$ & Yes & + & - & + & + & - & + & - \\
\hline & $\begin{array}{l}\text { Mobile comprehensive } \\
\text { expert team }\end{array}$ & $\begin{array}{l}\text { Yes/ but only in some } \\
\text { regions }\end{array}$ & No & Yes & - & NA & + & + & NA & - & - \\
\hline & $\begin{array}{l}\text { Team-based home } \\
\text { health care }\end{array}$ & Yes & Yes & Yes & - & - & - & + & - & - & + \\
\hline & $\begin{array}{l}\text { Team-based community } \\
\text { mental health for older } \\
\text { people }\end{array}$ & $\begin{array}{l}\text { Yes / but mental health } \\
\text { services for adults in } \\
\text { general (see team of CDCD } \\
\text { in Emilia Romagna for } \\
\text { psychogeriatrics) }\end{array}$ & $\begin{array}{l}\text { Yes / but mental health } \\
\text { services to adults with in } \\
\text { general }\end{array}$ & $\begin{array}{l}\text { Yes / but mental health } \\
\text { services to adults in } \\
\text { general }\end{array}$ & + & - & + & + & - & + & + \\
\hline & $\begin{array}{l}\text { Specialised psychiatric } \\
\text { home nursing care }\end{array}$ & No & No & Yes & NA & NA & + & + & NA & + & + \\
\hline & Day care/Day activity & Yes & Yes / very limited number & Yes / very limited number & + & - & + & + & + & - & - \\
\hline & Rehabilitation at home & Yes & Yes & Yes & - & - & -+ & + & - & - & - \\
\hline & $\begin{array}{l}\text { Information/ } \\
\text { Counselling }\end{array}$ & $\begin{array}{l}\text { Yes / but in Milan mostly } \\
\text { non-governmental or } \\
\text { private or web-based }\end{array}$ & Yes / only web-based & $\begin{array}{l}\text { Yes / personal \& web- } \\
\text { based }\end{array}$ & + & - & + & + & + & + & + \\
\hline
\end{tabular}




\begin{tabular}{|c|c|c|c|c|c|c|c|c|c|c|c|}
\hline \multicolumn{2}{|c|}{ Structures of dementia care service } & \multirow{2}{*}{$\begin{array}{l}\text { Italy } \\
\text { (I) } \\
\text { Is this service available? }\end{array}$} & \multirow[t]{2}{*}{$\begin{array}{l}\text { Poland } \\
\text { (PI) }\end{array}$} & \multirow[t]{2}{*}{ The United Kingdom (UK) } & \multicolumn{3}{|c|}{$\begin{array}{l}\text { Referral to } \\
\text { usual day care } \\
\text { activities }\end{array}$} & \multicolumn{4}{|c|}{$\begin{array}{l}\text { Referral to Meeting } \\
\text { Centre }\end{array}$} \\
\hline & & & & & 1 & $\mathrm{PI}$ & UK & 1 & $\mathrm{PI}$ & UK & $\mathrm{NL}^{*}$ \\
\hline \multirow[t]{2}{*}{$\begin{array}{l}\text { Informal } \\
\text { carers }\end{array}$} & Carer education & $\begin{array}{l}\text { Yes/usually non- } \\
\text { governmental }\end{array}$ & $\begin{array}{l}\text { Yes / very limited } \\
\text { options/ non- } \\
\text { governmental } \\
\text { organisations }\end{array}$ & Yes & + & - & - & + & + & - & + \\
\hline & Carer counselling & Yes & No & Yes & + & NA & - & + & NA & - & + \\
\hline \multirow[t]{2}{*}{$\begin{array}{l}\text { Civil } \\
\text { activities }\end{array}$} & Voluntary organisation & $\begin{array}{l}\text { Yes / at the Alzheimer's } \\
\text { association level }\end{array}$ & $\begin{array}{l}\text { Yes / at the } \\
\text { organisational level }\end{array}$ & $\begin{array}{l}\text { Yes / the Alzheimer's } \\
\text { Society at the regional } \\
\text { level }\end{array}$ & - & - & - & + & - & - & + \\
\hline & Self-help organisation & Yes & No & Yes & + & NA & + & + & NA & + & + \\
\hline \multicolumn{2}{|c|}{ Self - referrals } & & 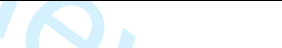 & & + & + & + & + & + & - & + \\
\hline
\end{tabular}

Legend: No=not available; Yes=available; (-)= do not refer in practice; $(+)=$ do refer in practice; NA=not applicable

* data from previous multi-centre implementation study (Dröes et al., 2004b) 
Differences between the care systems in the four countries are reflected in differences in the pathway to day care activities and MCSP. Taking into account the accessibility of dementia care services, the biggest limitations are visible in Poland compared to other countries. In particular, there is a lack of services providing home care and support including self-help organisations, carer counselling and a mobile integrated team.

The analysis of the pathways to regular day care activities for people with dementia in the three countries (I, PI and the UK) shows that there are several similarities i.e. referrals are mainly from the diagnostic and therapeutic settings like GPs or outpatients clinic specific for dementia, although self-referrals do occur in all three countries. In both Poland and the UK also specialised physicians refer to day care activities. In both Italy and the UK also home care and support services (healthcare professionals, team-based community mental health for older people, information/counselling services) or civil activities such as self-help organisations refer to day care.

But there are also differences between the countries, for example, regarding the availability of day care: formal dementia day care has been decommissioned in many areas of the UK over the past ten years. It was seen as expensive and stigmatising and was often not well utilised. The strategy instead has been to encourage people to seek more individualised support within their own homes and to continue to use regular community support networks. In many areas of the UK there are very little place-based day support structures for delivering support to people with dementia. The eligibility for funding social care is the responsibility of the Local Authority for social care.

The analysis of the pathway to MCSP shows that, compared to usual day care activities, Meeting Centres in Wroclaw (Poland) and in the described regions in Italy (Lombardia and Emilia Romagna) have wider access to the dementia pathway. In Poland, this is largely explained by the referral from other (general) day care/day activities. In addition, introducing the web-page information/counselling on dementia care connected to the Meeting Centres improved increased levels of self-referral.

In Italy, people living with dementia were also referred to the MCSP via mobile integrated teams and team-based home health care, as well as from civil activities such as voluntary organisations. Only in the UK there was seen no difference between regular day care and MCSP in terms of the pathway to care.

Comparison of the referrals to the MCSP in the three countries with referrals to MCSP in the Netherlands shows that the access to the MCSP is widest in the Netherlands: Referrals to MCSP are done from almost all structures of the Dutch dementia care system (see Table 1).

Changes in the accessibility to day care activities and support after introducing MCSP in the three countries involved (research question 3)

- Access to day care for the group with mild to moderate dementia and carer support According to data from expert panels, each of the described regions have benefitted from the introduction of the MCSP. This conclusion is based on the survey directed at the expert panel as a question. In Milan, the introduction of the Meeting Centres was the first step in the creation of a day care support network for people with mild to moderate dementia and their carers. Up until then this had been very limited, being existing options dedicated to people with more advanced dementia and often not offering carer support. A similar situation was observed in Wroclaw where, after introducing MCSP, the pathway to day care 
activities and support for people with dementia improved considerably. In fact, the combined MCSP is an innovative and integrated service, which previously did not exist in these regions and countries. The creation of such places gives their users access to care after the diagnosis of dementia and promotes early intervention. In the UK, the Meeting Centre was the only day support facility specifically for people with dementia and carers in the town where it was established (Droitwich Spa) and the surrounding villages. The only other existing specialist service for people with dementia and carers was a Dementia Café run by the Alzheimer's Society, once every two months for two hours, providing some opportunity for peer contact and information. The MCSP has now been incorporated into the local dementia care pathway, supported by a representation of key stakeholders from the pathway.

- Easier access, more self referrals

The broadened referrals to the Meeting Centres in Wroclaw and the involved regions in Italy showed that the access to day care activities in Meeting Centres was much easier than to some other centres providing day care activities. Data from the expert panel showed that Meeting Centres have been promoted through local media and the Internet. The families of people living with dementia could have direct access to the centres (self-referrals), as no referral from GP or specialist is required before accessing to Meeting Centres (people with dementia who do not have a formal diagnosis are invited to refer to memory clinics to get it, but this is not a pre-condition to access). This is significant because in Poland, for example, the waiting list in governmental medical facilities is often so long that it could delay admission to day care and support by several months.

In contrast to the centres in Italy and Poland, for the Meeting Centres in the UK relevant inclusion criteria are a formal diagnosis of dementia before accessing to them and being referred by an organisation on the Dementia Care Pathway prior to assessment by the Meeting Centre. The decision to have formal diagnosis as the usual criteria was taken because of the emphasis on improving diagnosis rates in the UK and ensuring that people were getting appropriate treatment and support. If people did self-refer because of local publicity about the Meeting Centre the general approach was that they were encouraged to clarify their diagnosis as a first step. Thus, taking into account the accessibility of dementia care service in the UK, the Meeting Centre model does not differ from other existing forms of care and support. However, it is seen as a crucial additional element/service in regions where previously the day care options were lacking or very limited.

\section{- Reduction of fear and stigma associated with dementia}

In UK experts taking part in the study pointed out another important issue: The improvement to the dementia pathway to care is linked with the reduction of fear and stigma associated with dementia, whilst the MCSP is promoting friendship and improving quality of life. Polish experts made a similar observation. In both the UK and Poland, it was recognised that a benefit of the Meeting Centre is that it is a facility "in a regular community setting away from health and social care premises" whilst also acting as a "useful conduit for prompt assistance and support from other agencies and professionals", because of the close collaboration network of the Meeting Centres with these services and professionals. This indicates that the centre forms an important bridge between the community and professional services. 
Taking into account the accessibility of the MCSP in the three countries (I, PI and the UK) compared to the Netherlands, it seems that both in Poland and Italy as in the Netherlands the MCSP model promotes an open access to the network of care and support. This is achieved by accepting self-referrals and by frequent public information about MCSP in the local media and on the Internet, as well as by focusing on the engagement of informal carers. In the Netherlands, a significant percentage of carers, just after reading articles on the combined support programme in the local newspaper, decided to sign in for the MCSP with their family member without formal referral (Dröes et al., 2004a). In a second instance confirmation of the diagnosis was requested from the GP. Although the situation regarding self-referrals in the UK Meeting Centre was more formalised, the publicity about the Meeting Centre and public events and meetings encouraged people to go forwards for diagnosis so that they could attend.

MCSP key elements contributing to the improvement of the pathway to day care in dementia in the three countries (research question 4)

A number of different factors were identified to have possibly improved the pathway to day care activities and carer support after introduction of the Meeting Centres. Figure 4 illustrates the findings of the expert panels in the three countries.

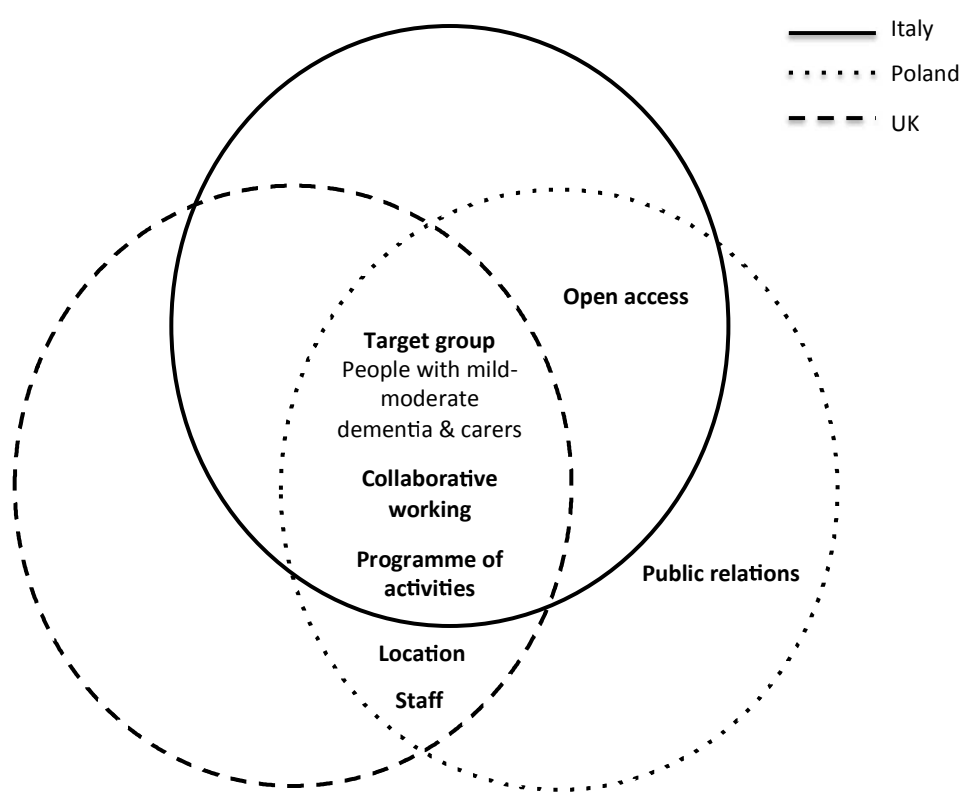

Figure 4. Key elements of MCSP

- Filling the gap in the care pathway

The most important factor emphasized by experts from all countries was the target group. Meeting Centres are designed for people at an early to moderate stage of dementia and for their carers. They fill a gap in the existing care pathway.

- Collaboration with other organisations 
Another important aspect is the collaboration between local organizations and the promotion of connection with local social and health services as well as voluntary and nonprofit organisations.

- User-centred, flexible programme

MCSP offers a flexible programme of enjoyable activities which can be adapted and tailored to meet individual needs, abilities and interests of the users.

- Open, easy accessible, location and skilled, friendly staff

In Italy and Poland, the open access was seen as fundamental and in both Poland and the UK an easily accessible location and skilled, friendly and enthusiastic staff were highlighted as crucial.

- Outreaching, information provision

Moreover, in Poland the focus on public relations - dissemination of information via the media, the Internet, producing leaflets, posters - was perceived as a very important key element in the improvement of the pathway to day care activities. Due to the spreading of information about the Meeting Centres, six months after the opening of the first Meeting Centre in Wroclaw there was already a waiting list of 80 people. This confirmed the great need for this type of support.

Meeting Centre as a central point of day care in the community at the beginning of the dementia journey (research question 5)

The experts from the three countries (Italy, Poland and the UK) agreed that the MCSP is beneficial to people with mild or moderate dementia, but it was felt to become less suitable when the dementia becomes more advanced. It was therefore emphasized that people should be timely provided with information about the Meeting Centre and what it could offer to themselves and their family, i.e. shortly after receiving a diagnosis of dementia or when they recognise the impairments in cognitive functions by themselves. This will make them aware of the existence of the MCSP as a central point of support in the local environment, but also of other services available in the locality or region that could benefit them. This is essential because services for people in the early stages of dementia are limited, regardless of the country and the type of health care and social service system. The Meeting Centres also provide people with the opportunity to build new local social networks with their peers who are facing similar challenges. Moreover, it is fundamental to support the family of the person with dementia from the very beginning and to offer people living with dementia stimulating activities and opportunities to socialise in the early stage of the disease. MCSP as post-diagnostic intervention has the potential to delay the onset of negative symptoms such as behavioural and mood disorders (BPSD) in the person living with dementia and to decrease depression and burnout in family carers.

\section{Conclusion and discussion}

The aim of the study was to gain insight into how innovation in the process and structure of post-diagnostic place-based care, in this case MCSP, could improve the care-pathway to day care activities for community dwelling people with dementia and support for their carers in different health care and welfare systems in Europe. The study was executed in three countries: Italy, Poland and the United Kingdom. The selected regions within these countries were all involved in the JPND-MEETINGDEM project that evaluated the adaptive implementation of the successful Dutch MCSP for people with dementia and their carers in 
other European countries. We first investigated the dementia care structure and pathways for people with mild to moderate dementia and their carers before and after implementation of MCSP in the three countries and we compared these with the pathways to MCSP in the Netherlands.

The results from our study showed that from the countries involved in the implementation of MCSP, the UK has the most structured pathway to post-diagnostic support for people living with dementia, provided by the National Health Service. However, dementia day-care services have been decommissioned in many areas and post-diagnostic support is delivered by a variety of different agencies from statutory, third sector, voluntary and community groups. In Italy and in Poland the pathways to post-diagnostic care in dementia, such as day activities, are less formal and less structured. Our study clearly showed the differences between the three countries regarding the organisation of the dementia care pathway (diagnostics, monitoring, services) and the availability of specialised health care and welfare services. In the UK there is a wide variety of interventions connected to the whole trajectory of dementia and, as mentioned, organised in a very structured and formal way. However, in the evaluated region in the UK a lack of services, including day care services, for people with mild dementia was identified, similar to Italy and Poland. In Italy and Poland the access to potential interventions seems to be much poorer and unstructured, and in Poland interventions very often end at the point of disclosure of the diagnosis to the person with dementia and carer. In Poland the weakest parts seem to be knowledge transfer to, and support for, informal carers. This finding is consistent with previous research from Hallberg et al. (2013), which evaluated dementia care and services within a European context. The study indicated that regardless of the health and social care service in the different countries, people living in the mild to moderate phase of dementia receive little attention and interventions. Moreover, another recent study conducted by Bieber et. al (2017) showed that across Europe, informal carers are mainly pro-active in seeking formal care on behalf of people with dementia, while GP are described as the most important profession supporting the access to formal care. At the same time it is noted that GPs because of their lack of knowledge about available support services cannot always successfully meet this expectation of being the first contact point in the pathway to care. Moreover, according to Alzheimer Europe report (Diaz-Ponce et. al, 2014) these problems may be summarised as system-related barriers, including long waiting lists to see a specialist, difficult access to diagnostic services, as well as lack of assistance directed to cares in navigating the system. Beyond Europe similar problems in the dementia care pathway are described. A recent study conducted in Taiwan, for example, pointed out the lack of knowledge among Taiwanese support and care providers and the carers on the availability and accessibility of dementia services (Li \& Fang, 2016).

Taking into consideration the changes after introducing MCSP, it appeared that MCSP had a positive impact on the dementia pathways to day care activities in all countries, which could be described as system-related. MCSP fills an important gap in the post-diagnostic support process, allowing timely interventions as well as enhancing access of community dwelling people with dementia and their carers to the available support and care. In particular, the open access to Meeting Centres and the ability to self-refer was particularly valued in Italy and Poland. In all settings in Italy and Poland the open access to the Meeting Centres offered people with dementia and their carers the opportunity to make contact and engage with the care network. In all countries the MCSP improved access to day care activities. 
Although the referral structure in the UK was more formal, the UK experts who were interviewed confirmed that the socially integrated Meeting Centres reduced fear and stigma around dementia. The local publicity and open meetings promoted an accessible and friendly image of care and support. In the Netherlands, where the programme has been available since 1993 and currently 144 Meeting Centres exist, the accessibility is widest. This is also because almost all levels of the community based Dutch dementia care and welfare structure refer to the Meeting Centres.

The present study demonstrated that it is possible to transfer the MCSP model successfully to different European countries. This conclusion differs from findings of Boustani et al. (2011) who predicted that the type of health care system in which an integrated model of support is implemented might limit its future implementation into other legal and organisational contexts. All countries emphasised that the target group of MCSP, the balanced programme of activities for people with dementia and their carers and the close collaboration between the Meeting Centre and other health care and social organisations in the region were key elements that contributed to the improvement of the pathway to day care in dementia. In addition, the location, staff and the open access to the Meeting Centre were emphasised as important factors. Public relations were identified as crucial by the Polish expert panel.

According to Westfall et al. (2007) translating and disseminating new models of care into day-to-day practice can take a long time, with some research suggesting that the average is more than 17 years. The MEETINGDEM project is an excellent example of how the innovation of services may be successfully implemented in a relatively short period of 18 months, taking into account the country specific context (Mangiaracina et al., 2016) and how it may positively influence the pathway to dementia care in these countries.

The present study highlights that people in the early stages of dementia (mild to moderate) will have the most benefit from MCSP and therefore Meeting Centres are recommended to maintain their focus specifically on this target group. In all countries that participated in this study interventions for people living with mild to moderate dementia tend to be fragmented among local organisations, similar to the Netherlands before the implementation of MCSP. MCSP could help to overcome this fragmentation. According to Dröes (1996) due to the close collaboration between Meeting Centres and other care and welfare providers the contact with referrers improved and helped to organise a comprehensive, combined, and effective support programme for people with dementia and their carers under "one roof". In fact, an integrated service as MCSP was not existent before in the involved regions in these countries. Thus, the implementation of MCSP gave the opportunity to promote early intervention and timely diagnosis, two crucial steps in the pathway to dementia care.

\section{Conclusion}

This study shows that MCSP could play an important role in the beginning of the pathway to care, more specifically to day care activities for people with mild to moderate dementia and support for their informal carers in European countries. MCSP fills (part of) the gap between diagnosis and residential care and it can therefore be seen as a pillar of post-diagnostic care and support. Further dissemination of Meeting Centres in Europe may have a multiple impact both on the structure of dementia services in European countries and on the pathways to care of people living with dementia and their carer(s). The Meeting Centre's coordinator may also refer people with suspected dementia to specialists for consultation 
and diagnostic assessment at an early stage or, in more advanced stages, to long-term healthcare facilities. As such, the MCSP could be defined as an integrated care service, i.e. as a coherent and coordinated set of support activities which are planned, managed and delivered to its users with the collaboration of professionals, local organisations and informal carers (Raak et al., 2003).

\section{Strengths and limitations}

The strength of this study was that the day care pathways were compared across three very different European countries. It highlighted how implementation of a new model of care may improve the organisation of post-diagnostic day care and support for people with dementia. To date, no other studies have previously carried out such a comparison. For this comparison we utilised a standard template to help describe the pathway to care in a reliable manner.

This study had also some limitations. First, using the standard template for the description of pathways to care may have led to a simplified representation of dementia care practice. However, an in-depth comparison appeared to be challenging particularly because of the differences in health and welfare and financing systems and differences in law/regulations between the countries, or even regions within countries. Due to time restrictions we based our study on the description of one or two regions per country. As a consequence one should be cautious to generalize the study findings to other countries or regions. Another limitation is that the pathway to care after implementation of MCSP was based on a small number of Meeting Centres per country/region and thus on a limited number of its participants (around 15 dyads of people with dementia and carers per centre). As the centres had recently be opened a lot of publicity was made to recruit participants. This will have influenced the referrals to the Meeting Centres. To see if the pathways to day care activities have been changed structurally by MCSP we recommend to repeat the study in two or three years.

Scientific relevance and practical implications of the study

As far as we know this is the first study to investigate how implementation of a new integrated support program for people with dementia and their carers (MCSP) in different European countries influenced the pathway to dementia care, more specifically day care activities, in these countries. We took into consideration the meso- or organisational level' of care services and the 'macro- or health care system level'. The study findings contribute to better understanding of the key elements of the combined MCSP that seem crucial in improving the existing pathways to dementia day care.

An important point arising from this study, relevant for both scientists and practitioners is that a step-wise implementation process, involving all dementia care, welfare and volunteer organizations is beneficial not only for the success of the Intervention itself (MCSP) but also for the quality of the process of care in dementia. Starting from the needs of people with dementia and their carers and involving available relevant organisations and services appears an effective way to embed new interventions into the existing care and welfare system and fill potential gaps. Moreover, disseminating the model of Meeting Centres across the countries that were involved in this study and across Europe is expected to result in improvement of post-diagnostic dementia care independent of the existing health system. This will promote the autonomy of many persons living with dementia, support them to adapt to the changes dementia brings into their lives and improve their, and their family 
carers', health and quality of life.

Conflict of Interest: none.

\section{Description of authors' roles:}

D. Szcześniak wrote the paper, collected the data and conducted the data analysis. R.M Dröes designed the study, assisted with and supervised the writing of the article. F. Meiland supervised the data collection and assisted with writing the article. D. Brooker supervised the data collection and assisted with writing the article. E. Farina supervised the data collection and assisted with writing the article. R. Chattat supervised the data collection and assisted with writing the article. S.C. Evans supervised collection of the data and assisted with writing the article. S.B. Evans collected the data and assisted with writing the article. F.Saibene collected the data. K. Urbańska collected the data. J. Rymaszewska supervised the data collection and supervised with writing the article.

Acknowledgements: This is an EU Joint Programme - Neurodegenerative Disease Research (JPND) project. The project is supported through the following funding organisations under the aegis of JPND: Italy, Ministry of Education and Ministry of Health; Netherlands, ZonMw; Poland, Narodowe Centrum Badań i Rozwoju; UK, Economic and Social Research Council. 


\section{References:}

1. Bieber, A., Stephan, A., Verbeek, H., Verhey, F., Kerpershoek, L., Wolfs, C., ... \& Sjölund, B. M. (2017). Access to community care for people with dementia and their informal carers. Zeitschrift für Gerontologie und Geriatrie, 1-7.

2. Boustani, M. A., et al. (2011). Implementing innovative models of dementia care: The Healthy Aging Brain Center. Aging \& Mental Health, 15(1), 13-22. doi: 10.1080/13607863.2010.496445

3. Brooker, D., Fontaine, J. L., Evans, S., Bray, J., and Saad, K. (2014). Public health guidance to facilitate timely diagnosis of dementia: ALzheimer's COoperative Valuation in Europe recommendations. International Journal of Geriatric Psychiatry, 29(7), 682-693. doi: 10.1002/gps.4066

4. Central Statistical Office (2015). Health and Health Care in 2014. Warsaw.

5. del-Pino-Casado, R., Frías-Osuna, A. and Palomino-Moral, P. A. (2011), Subjective Burden and Cultural Motives for Caregiving in Informal Caregivers of Older People. Journal of Nursing Scholarship, 43, 282-291. doi: 10.1111/j.1547-5069.2011.01407.x

6. Department of Health (2009) Living well with dementia: A National Dementia Strategy. London.

7. Diaz-Ponce, A., Croy, A., Schrobiltgen, C., Steyaert, J., Verschraegen, J., Ilieva, V., ... and Georghiou-Kyriacou, I. (2014). Dementia in Europe. Yearbook 2014-National care pathways for people with dementia living at home.

8. Dröes, R.M., et al. (2017). Comparison of the adaptive implementation and evaluation of the Meeting Centers Support Program for people with dementia and their family carers in Europe; study protocol of the MEETINGDEM project. BMC Geriatrics (in press)

9. Dröes, R. M., Meiland, F. J. M., Schmitz, M. and van Tilburg, W. (2004a), Effect of combined support for people with dementia and carers versus regular day care on behaviour and mood of persons with dementia: results from a multi-centre implementation study. International Journal of Geriatric Psychiatry, 19, 673-684. doi:10.1002/gps.1142

10. Dröes, R. M., Van Der Roest, H. G., Van Mierlo, L., \& Meiland, F. J. (2014). Memory problems in dementia: adaptation and coping strategies and psychosocial treatments. Expert Review of Neurotherapeutics, 11(12), 1769-1782 doi: 10.1586/ern.11.167

11. Dröes, R.M., van Mierlo, L.D., van der Roest, H.G., Meiland, F.J.M. (2010). Focus and effectiveness of psychosocial interventions for people with dementia in institutional care settings from the perspective of coping with the disease. Non-pharmacological Therapies in Dementia, 2,139-161.

12. Dröes, R.M., et al. (2004b). Variations in meeting centers for people with dementia and their carers: results of a multi-centre implementation study. Archives of Geriatrics and Gerontology, suppl. 9: 127-148. doi: http://dx.doi.org/10.1016/j.archger.2004.04.020

13. Dröes, R. M. (1996). Amsterdamse Ontmoetingscentra; een nieuwe vorm van ondersteuning voor dementerende mensen en hun verzorgers. Eindrapport: Thesis Publishers.

14. Hallberg, I. R., et al. (2013). Dementia Care in Eight European Countries: Developing a Mapping System to Explore Systems. Journal of Nursing Scholarship, 45(4), 412-424. doi: 10.1111/jnu/12046

15. Kerpershoek, L., et al. (2016). Access to timely formal dementia care in Europe: protocol of the Actifcare (ACcess to Timely Formal Care) study. BMC Health Services Research. 16,423, doi: 10.1186/s12913-016-1672-3 
16. Jones, J., and Hunter, D. (1995). Consensus methods for medical and health services research. BMJ: British Medical Journal, 311(7001), 376. doi: https://doi.org/10.1136/bmj.311.7001.376

17. Mangiaracina, F. et al. (2017). Not re-inventing the wheel: the adaptive implementation of the meeting centres support programme in four European counties. Aging \& Mental Health, 21, 4048. doi: http://dx.doi.org/10.1080/13607863.2016.1258540

18. Meiland, F.J.M., Dröes, R.M., Lange, J. de, Vernooij-Dassen, M.J.F.J. (2005). Facilitators and barriers in the implementation of the meeting centres model for people with dementia and their carers. Health Policy, 71(2), 243-53. doi: http://dx.doi.org/10.1016/j.healthpol.2004.08.011

19. Millard, F. and Baune, B. (2009). Dementia - who cares? A comparison of community needs and primary care services. Australian Family Physician, 38(8), 642-649.

20. Li, C. P., and Fang, Y. W. (2016). Care pathway networks as a guideline for people with Dementia in Taiwan. Technology and health care, 24(s1), 337-344.

21. OECD (2015). Addressing Dementia: The OECD Response, OECD Publishing: Paris. DOI: http://dx.doi.org/10.1787/9789264231726-en

22. Prince, M. J., et al. (2015). The burden of disease in older people and implications for health policy and practice. The Lancet, 385(9967), 549-562. DOI: http://dx.doi.org/10.1016/S01406736(14)61347-7

23. Prince, M. J., Comas-Herrera, A., Knapp, M., Guerchet, M. and Karagiannidou, M., (2016). World Alzheimer Report 2016: Improving healthcare for people living with dementia coverage, Quality and costs now and in the future. Alzheimer's Disease International (ADI): London. (available from: https://www.alz.co.uk/research/WorldAlzheimerReport2016.pdf)

24. Raak, A., Mur-Veeman, I., Hardy, B., Steenbergen, M. and Paulus, A. (2003). Integrated care in Europe. Description and comparison of integrated care in six EU countries. Maarssen: Elsevier Gezondheidszorg.

25. Samsi, K., and Manthorpe, J. (2014). Care pathways for dementia: current perspectives. Clinical Interventions in Aging, 9, 2055-2063. doi: 10.2147/CIA.S70628

26. Schrijvers, G., van Hoorn, A. and Huiskes, N. (2012). The Care Pathway: Concepts and Theories: An Introduction. International Journal of Integrated Care, 12 (Special Edition Integrated Care Pathways), e192.

27. van der Lee, J., Bakker, T. J., Duivenvoorden, H. J. and Dröes, R. M. (2014). Multivariate models of subjective caregiver burden in dementia: a systematic review. Ageing Research Reviews, 15, 7693. doi: 10.1016/j.arr.2014.03.003

28. Westfall, J. M., Mold, J. and Fagnan, L. (2007). Practice-based research-“Blue Highways" on the NIH Roadmap. Jama, 297(4), 403-406. doi:10.1001/jama.297.4.403

29. Wilcock et al. (2013). Tailored educational intervention for primary care to improve the management of dementia: the EVIDEM-ED cluster randomized controlled trial. Trials, 14, 397 doi: 10.1186/1745-6215-14-397 